REVISTA ANDALUZA DE ANTROPOLOGÍA

NÚMERO 18: MIRADAS DESDE LA ANTROPOLOGÍA AMBIENTAL.

ABRIL DE 2020

ISSN 2174-6796

[pp. 1-3]

https://dx.doi.org/10.12795/RAA.2020.18.01

\title{
“MIRADAS DESDE LA ANTROPOLOGÍA AMBIENTAL”
}

Este número monográfico de la Revista Andaluza de Antropología quiere ofrecer una panorámica del actual estado de los estudios socio-antropológicos sobre el amplio campo de las relaciones que los seres humanos mantienen con el medioambiente en el que viven y del que forman parte. Unidos por el denominador común de la superación de dicotomías como naturaleza/cultura, medio ambiente/sociedad, animal/humano, entre otras, los distintos trabajos que conforman su contenido abordan temas y problemas diversos, desde perspectivas teórico-metodológicas diferentes, ofreciendo una muestra de la investigación socio-ambiental contemporánea relacionada con el contexto mediterráneo y latinoamericano.

Los textos que se incluyen pretenden, de este modo, constituir una buena representación de las preocupaciones socio-antropológicas existentes sobre cuestiones ambientales muy precisas en una época ciertamente crítica a escala global. Con ella se tornan más necesarias que nunca nuevas miradas que ahonden en la comprensión de procesos socioecológicos particulares, en el diseño de alternativas contra el deterioro ecológico o en el análisis crítico de las políticas ambientales. Estas aspiraciones, que en buena medida vienen marcadas por la realidad convulsa y cambiante que se esboza en los artículos, precisan asimismo de aproximaciones que conceptualicen de manera original las relaciones humano-ambientales y, al mismo tiempo, utilicen nuevas herramientas que profundicen, de otra forma y con otros postulados, en un terreno donde lo biológico, lo político, lo sociocultural y lo económico se fusionan.

Así, entre las siete contribuciones se incluye en primer lugar una reflexión de carácter teórico-metodológico que realizan Santiago M. Cruzada y Garry Marvin sobre la necesaria inclusión del animal como coprotagonista, y no meros objetos inermes, en 
las relaciones ecológicas que mantienen con los seres humanos en diferentes contextos. Según los autores, en la actual "encrucijada ambiental" las herramientas teóricas y metodológicas que posee la Antropología pueden ayudar a la mejor comprensión de dichas relaciones y, con ello, a estimular el entendimiento acerca de cómo y por qué se construyen ciertas ecologías.

El artículo de Ernesto Martínez se centra en el análisis de cómo la denominada "agricultura ecológica" se ha incorporado al universo simbólico de los sectores rurales protagonistas de las producciones agropecuarias de ciertos territorios, como los de las serranías andaluzas, que particularmente se hallan dependientes de los instrumentos de apoyo a las rentas implementadas por la Política Agraria común de la UE. El texto se pregunta de manera sugerente hasta qué punto se ha incorporado en las estrategias económicas de los grupos domésticos de pequeños y medianos productores agrarios andaluces los dictámenes de una política ecológica externa que idealiza "lo verde".

Siguiendo en el mundo agrario, aunque en un contexto geográfico diferente como es el de la montaña de Cerdeña, el trabajo de Domenica Farinella aborda las formas en las que los ganaderos de ovino han desarrollado ciertas acciones que les permiten adaptar el modelo agropastoral tradicional a las condiciones de la denominada "modernización agrícola" y a la inserción de su producción en un mercado global, proceso no exento de contradicciones e incertidumbres y muy dependiente de los factores medioambientales.

También relacionado con los contextos rurales, el trabajo de Jaume Franquesa se centra en las respuestas y resistencias de la población local en territorios de la Cataluña sur, la cual se halla sometida a la presión de promotoras de instalación de aerogeneradores que amenazan seriamente con la transformación radical de las condiciones de vida, no sólo de esas poblaciones, sino del medio ambiente sobre los que se sustentan y con el que se relacionan.

En un terreno intermedio, el artículo de Agustín Coca, Félix Talego y Ángel de Río se interesa por el papel de los grupos ecologistas, de raíces y composición mayoritariamente urbanas, en el contexto de los movimientos sociales desarrollados en Andalucía desde los años 70. Se hace un recorrido por sus trayectorias y posicionamientos, reflexionando sobre la significación y controversias que contiene la propuesta política de las entidades ecologistas en el contexto actual de desarrollo "crecentista", para focalizar su atención en el conflicto ambiental que está teniendo lugar con respecto a la deforestación del Parque Natural "Los Alcornocales" y en la confluencia existente entre el movimiento ecologista y determinados colectivos rurales locales.

En cierta forma conectado con el anterior, pero fijándose en un fenómeno como el del movimiento animalista, el artículo de Huan Porrah, tomando como caso el conflicto surgido en relación al servicio de burro-taxi en la localidad costasoleña de Mijas, plantea 
el debate sobre la confrontación entre formas de entender las relaciones humano-animal de bases rural y campesina de los habitantes nativos y la visión urbanita de un animalismo descontextualizado con respecto a las mismas, visión alejada de las condiciones socioeconómicas y medioambientales a las que dichas relaciones responden, en cuya expresión se ponen de manifiesto prejuicios sociales y culturales de superioridad ética y moral del mundo urbano desde el que se juzgan las formas culturales de los locales.

El último artículo es obra de Felipe González, que analiza el papel de los vendedores ambulantes de la ciudad de Toluca (México) como actores que, en tensión con los agentes institucionales y los sectores que los hegemonizan, dan uso y sentido al espacio público, en general, y a la calle, en particular, contribuyendo con ello al mantenimiento de una ciudad socio-biodiversa, y a la comprensión del medioambiente urbano.

Cierra este número de la revista una reseña, elaborada por Yolanda Aixelá, al libro de Pardo-Tomás, Zarzoso y Menchero (2019) Cuerpos mostrados..., donde los autores se preguntan sobre las similitudes y diferencias existentes en la exhibición de los cuerpos humanos entre los siglos XVII y XX, con especial énfasis en las ciudades de Madrid y Barcelona. Para la autora de la reseña, la formulación de esta obra, aunque de talante histórico, se produce en términos profundamente antropológicos dados los estudios de caso donde se apoya el texto.

Con las propuestas que se presentan en este nuevo número monográfico de la Revista Andaluza de Antropología se pretende reconocer las muchas y diversas maneras en que los seres humanos se relacionan con sus entornos, añadiendo nuevas ideas a viejos debates o, directamente, abriendo nuevas discusiones que permiten comprender de manera más ajustada cómo son, se desarrollan y producen relaciones socioecológicas particulares, enriqueciendo con ello un campo de la Antropología que creemos sumamente importante para entender los tiempos que corren.

Desde el Consejo Editorial quisiéramos finalizar esta breve introducción temática agradeciendo la labor de las personas y organismos que han facilitado que este número 18 vea la luz, así como manifestar especialmente nuestro reconocimiento a todas las revisoras y revisores que han contribuido al aumento de la calidad y rigurosidad de los textos presentados.

El Coordinador, Antonio Luis Díaz Aguilar

Universidad Pablo de Olavide 